\title{
Is there a link between the circulating renin- angiotensin system and coronary disease? A buoyant view
}

\author{
Michael H Alderman
}

That plasma renin activity bears a relation to the occurrence of myocardial infarction derives largely from the seminal work of Brunner, Laragh and Gavras, and their colleagues during the late 1960 s and early 1970s. ${ }^{12}$ In experimental animals, a high plasma renin state was associated with a variety of adverse vascular effects, including myocardial infarction. At the same time, a retrospective review of hypertensive patients revealed that those with the highest plasma renin to sodium profile, based on a nomogram designed by Laragh, were at the greatest risk of both strokes and heart attacks. ${ }^{3}$ A relation between the renin-angiotensin system and myocardial infarction has subsequently been found in a variety of animal studies, clinical research, observational cohort studies, and secondary prevention trials. These various strands of evidence together provide the biological rationale and the observational evidence to support the view that, at least in hypertensive subjects, a raised plasma renin activity is associated with an increased likelihood of myocardial infarction.

\section{Animal studies}

The earliest evidence that hyperreninaemia could produce vascular damage is to be found in the studies of Winternitz et al, who demonstrated severe arterial damage in nephrectomised dogs given renin injections. ${ }^{4}$ Subsequent studies by Masson et al produced similar findings in rats. ${ }^{5}$ In these studies, the renin effect was amplified by aldosterone administration, and virtually eliminated by sodium deprivation. Finally, a variety of studies in rabbits and rats, using mild pressor doses of angiotensin II, produced lesions of early myocardial infarction. ${ }^{67}$ These later studies were the first to directly link angiotensin II to the characteristic pathology of myocardial infarction. These same experiments also revealed vascular lesions in the cerebrovascular and renal circulation.

Chobanian and colleagues have more recently shown that converting enzyme inhibition is capable of retarding atheroma formation in the descending aorta of rabbits in

\section{Glossary of trials}

SOLVD: Studies of Left Ventricular Dysfunction whom the lipid profile had not been altered. ${ }^{8}$ These, and other studies in which pharmacological blockade of the renin system has been employed, confirm the toxic potential of angiotensin II on the coronary vasculature.

\section{Clinical studies}

It has been known for more than a decade that converting enzyme inhibition is capable of augmenting coronary blood flow in patients with symptomatic coronary insufficiency. ${ }^{9}$ It is also known that converting enzyme inhibition, perhaps through bradykinin increase, produces an antiarrhythmic effect. More recently, converting enzyme inhibition has been shown to have a favourable influence on the postmyocardial infarction process of remodelling. This latter effect is probably related to the inhibition of collagen synthesis. Moreover, patients treated with converting enzyme inhibition at an early and asymptomatic phase of left ventricular dysfunction have an improved ejection fraction, extended exercise tolerance, and are less likely to have a rise in left ventricular end diastolic volume. ${ }^{10}$ It is believed that these effects reflect the ability of angiotensin converting enzyme (ACE) inhibition to protect myocyte integrity, suppress pressor hormones, potentiate local vasodilatation, reduce afterload, and enhance myocardial perfusion.

A series of studies by Dahlöf, Herlitz, Aurell and Hansson provides powerful direct evidence that the reversal of vascular changes known to lead to myocardial infarction is possible in hypertensive patients through blockade of the renin-angiotensin system. Vascular changes that occur in hypertensive patients may persist, even in the face of effective hypotensive therapy with certain pharmacological agents. ${ }^{11}$ Indeed, blood pressure reduction and reversal of vascular effects of raised blood pressure may not be inextricably linked. Dahlöf and colleagues sought to find out whether there was a difference between drugs and, specifically, whether a renin blocking treatment would produce better vascular results. Left ventricular hypertrophy is both a consequence of high blood pressure and a marker of increased cardiovascular disease risk. Reversal of cardiac hypertrophy is therefore likely (although not proven) to be a desirable outcome of antihypertensive therapy. A good deal of evidence supports the view that angiotensin II has both mitogenic properties and growth stimulating effects that affect vas- 
Figure 1 Percent change in left ventricular mass (LVM), posterior wall thickness (PWT), and relative wall thickness (RWT) from baseline to six months of treatment with enalapril $(n=14)$ and hydrochlorothiazide $(n=14)$, respectively. ${ }^{\star} P=0.026 ;+P=$ $0 \cdot 014 ; \neq P=0.001$

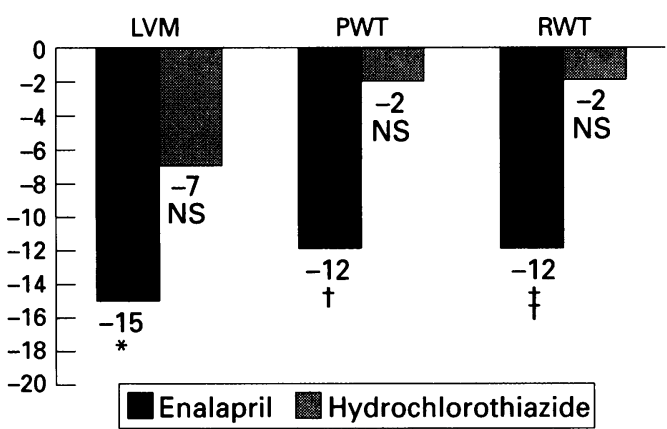

cular smooth muscle cells, fibroblasts, and cardiac myocytes. These growth effects may contribute to left ventricular hypertrophy.

To determine whether antihypertensive therapy that blocked the renin-angiotensin system would produce greater reversal of hypertrophy, 28 previously untreated hypertensive subjects were randomly allocated to either enalapril or hydrochlorothiazide monotherapy. Effects on cardiac and other vascular structures were assessed after six months of treatment. Blood pressure control was similar between the two groups, although the enalapril group achieved a lower (133/88 $v 147 / 94 \mathrm{~mm} \mathrm{Hg}$ ) final level. Enalapril, as expected, reduced both ACE and angiotensin II levels. Hydrochlorothiazide did not affect converting enzyme levels, but significantly increased angiotensin II levels. There were no significant differences in plasma renin activity. Total peripheral resistance was increased by hydrochlorothiazide and sharply reduced by enalapril. Cardiac changes were sharply different between the groups. Hydrochlorothiazide patients showed a minimal, non-significant fall in left ventricular mass. By contrast, the enalapril treated subjects all had significantly reduced left ventricular mass, posterior wall thickness, and relative wall thickness (fig 1). All of these differences between the two groups were significant. Stepwise regression analysis suggested that the cardiovascular structural changes were more dependent upon changes in the circulating renin-angiotensin system than on blood pressure change. Thus, the type of treatment was the most important determinant of outcome, accounting for $40-50 \%$ of the variance for the different elements of cardiac structure. Both reversal of cardiac hypertrophy and reduced peripheral resistance are believed to be valuable components of antihypertensive therapy. Both are shown here to be positively associated with blockade of the renin-angiotensin system.

Table 1 Unadjusted and adjusted incidence of myocardial infarction per 1000 personyears, according to renin profile ${ }^{\star 12}$

\begin{tabular}{lcrrll}
\hline & \multicolumn{2}{l}{ Renin profile } & & \\
\cline { 2 - 4 } Variable & High & Normal & Low & Rate ratiof \\
\hline No of events & 7 & 15 & 5 & - \\
Follow up (person-years) & 539.3 & 2851.8 & 1519.8 & - \\
Unadjusted incidence & 13.0 & 5.3 & 3.3 & $3.9(1.2$ to 12.3$)$ \\
Adjusted incidence & 14.7 & 5.6 & 2.8 & $5.3(3.4$ to 8.3$)$ \\
\hline
\end{tabular}

*The incidence was adjusted for distributional differences in age, sex, and race, with the entire study population as the standard.

tThe rate ratio is that between the high profile and low profile groups, values in parentheses are $95 \%$ confidence interval.
In sum, a solid body of clinical research provides the pathophysiological basis for a strong direct effect of the renin-angiotensin system on the health of the heart. However, intriguing as such mechanistic findings may be, they only provide the rationale for a hypothesis that must be confirmed through prospective studies linking the renin system to cardiovascular outcomes.

\section{Human cohort studies}

A POSITIVE FINDING IN HYPERTENSIVE PATIENTS

A prospective cohort study, begun in 1980, of a large New York community-based population of systematically treated, mostly mild and moderate hypertensive subjects, confirmed the strong association between high pretreatment plasma renin/urinary sodium profile and subsequent myocardial infarction morbidity and mortality. ${ }^{12}$ In this study, 1717 subjects with mild to moderate hypertension had plasma renin and 24 hour urine sodium measured after at least three weeks without antihypertensive treatment. The group had a mean age of 53 years, was $36 \%$ white, and $67 \%$ male. Participants were classified on the basis of the Laragh renin/urinary sodium profile into high (H) $(12 \%)$, normal $(\mathrm{N})(56 \%)$, and low (L) $(32 \%)$. Mean entry pressure by renin profile status was $151 / 100 \mathrm{~mm} \mathrm{Hg}$ for $\mathrm{H}, 151 / 97 \mathrm{~mm}$ $\mathrm{Hg}$ for $\mathrm{N}$, and $151 / 96 \mathrm{~mm} \mathrm{Hg}$ for L. Treatment was prescribed without knowledge of renin status. Blood pressure control was similar and successful for each group.

During an average of 4.3 years of follow up, there were 27 events. The rate in high renin subjects $(14 \cdot 7 / 1000$ patient years) compared to the low renin group $(2 \cdot 8 / 1000$ patientyears) yielded a highly significant rate ratio of $5 \cdot 3$ (table 1). Although only nine stroke events occurred, they have no association with renin, and this was true for non-cardiovascular mortality as well. This pattern held for smokers and non-smokers, high and low cholesterol subjects, and for those with and without a raised fasting blood glucose (fig 2). Multivariate analysis revealed that the renin profile was independently associated with the incidence of myocardial infarction, as was cholesterol, age, race, previous cardiovascular disease, smoking, and left ventricular hypertrophy. While these findings held for the group as a whole, more than $80 \%$ of events occurred in men in whom the renin to myocardial infarction relation was particularly powerful. This was not detected in women, perhaps because of the paucity of events. These findings have now been extended through longer follow up with more subjects. ${ }^{13}$

\section{A negative reply}

Publication of the New York study stimulated Meade and coworkers at the British Medical Research Council (MRC) to revisit a population based cohort in which both blood pressure and plasma renin activity had been ascertained during the $1970 \mathrm{~s}^{14}$ Their objective 


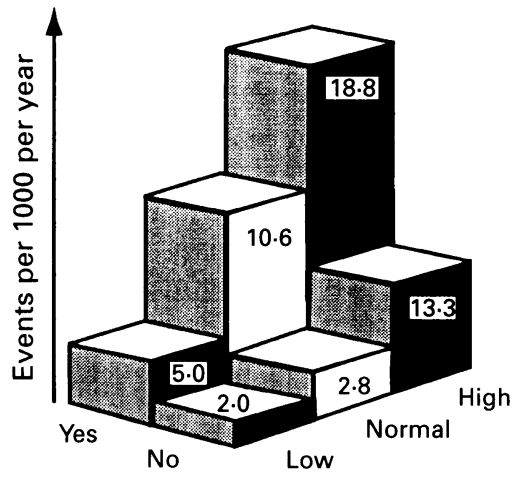

No smoking Renin profile
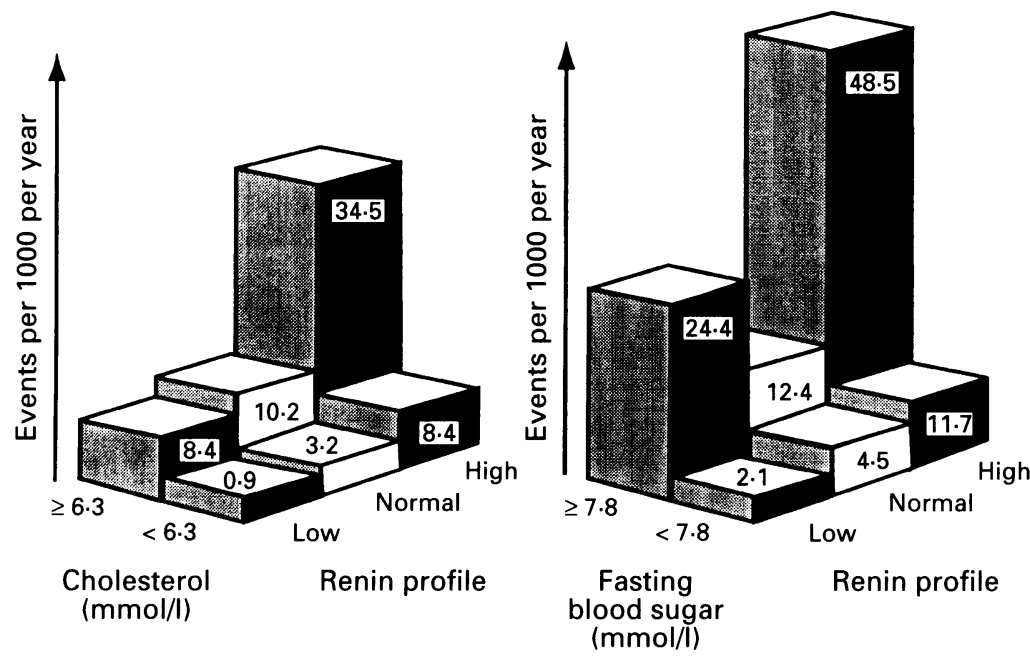

Figure 2 Incidence of myocardial infarction, as adjusted for age, sex, and race, according to renin profile and smoking status, cholesterol level, or fasting blood glucose level.

was to determine the subsequent morbidity and mortality experience of the male workers who had participated in an earlier MRC cross sectional study. The existence of a national health service, rigorous pursuit of survivors, and a centralised mortality ascertainment facility made the task possible.

The population upon which the recent study is based was $80 \%$ of the 883 working males who had volunteered for the original study from a variety of industrial organisations near London. The present study population excluded those 51 who were initially diagnosed with hypertension and the 29 who had an myocardial infarction before the initial examination. During follow up through 1991, there were 35 non-fatal and 51 fatal myocardial infarctions. Fifty eight other participants succumbed for other reasons. For the group as a whole, mean blood pressure was $136 / 84 \mathrm{~mm}$ $\mathrm{Hg}$. For those sustaining an infarction, initial pressure was significantly higher $(143 / 87 \mathrm{~mm}$ $\mathrm{Hg}$ ). Cases also had higher initial mean body mass indices, higher total serum cholesterol, and a non-significantly greater tendency to smoke than did those not sustaining a myocardial infarction.

As expected, there was an inverse relation between plasma renin activity and systolic blood pressure. The plasma renin activity of those who did and those who did not succumb to ischaemic heart disease was indistinguishable $(642.8 v 674.6 \mathrm{pmol} / \mathrm{litre} / \mathrm{h})$. However, when the group as a whole was stratified by tertiles of blood pressure, those in the highest blood pressure category were at greatest risk of myocardial infarction. By contrast, stratification by tertiles of renin yielded groups with roughly identical event rates (table 2). However, when those in the highest tertile of blood pressure were further stratified by plasma renin activity, a clear stepwise trend was shown, with the highest rate observed for those in the highest third of renins having the highest event rate. When the analysis was limited to the 242 subjects with initial blood pressure greater than $160 / 95 \mathrm{~mm} \mathrm{Hg}$, consistent with the criteria of the earlier New York study, those in the highest renin tertile had a relative risk of 1.26 (95\% confidence interval 0.63 to 2.56) compared with the lowest tertile. Furthermore, when the experience of the top $12 \%$ of the renin group was compared with the lowest $32 \%$ (a distribution similar to the high and low renin/sodium groups in the Alderman paper), there was a relative risk of 1.88 , with a $95 \% \mathrm{CI}$ of 0.78 to 4.54 , which did not include the point estimate found by Alderman et al of 5.3. In a Cox proportional hazards analysis, only age, cholesterol, body mass index, and systolic pressure were independently and significantly related to myocardial infarction.

On the basis of these data, the investigators concluded that no relation existed between plasma renin activity and myocardial infarction in normotensive men. They indicated that the data do not exclude the possibility that, among those with high blood pressure, a renin to myocardial infarction relation may exist, but contended that their data added no support for such a relation.

In an effort to identify potential causes for the apparent inconsistencies between the two prospective investigations, Meade noted differences in the composition of the two study populations. By including more blacks and women, the New York study group had $40 \%$ black men in the low renin group as opposed to only $18 \%$ white men. It is possible, claim Meade et al, that correction for this heterogeneity through multivariate analysis may not

Table 2 Plasma renin activity, systolic blood pressure, and coronary artery events

\begin{tabular}{|c|c|c|c|}
\hline \multirow[b]{3}{*}{ Blood pressure } & \multicolumn{3}{|c|}{ Plasma renin activity } \\
\hline & $\begin{array}{l}\text { Lowest } \\
(<572 \mathrm{pmol} / \mathrm{l} / \mathrm{h})\end{array}$ & $\begin{array}{l}\text { Middle } \\
(572-1016 \mathrm{pmol} / \mathrm{l} / \mathrm{h})\end{array}$ & $\begin{array}{l}\text { Highest } \\
(>1016 \text { pmol/l/h) }\end{array}$ \\
\hline & \multicolumn{3}{|c|}{ Events per 1000 years of observation (No of events) } \\
\hline Lowest $(<130 \mathrm{~mm} \mathrm{Hg}$; mean $=118)$ & $5 \cdot 60(8)$ & $5 \cdot 49(9)$ & $5 \cdot 53(8)$ \\
\hline Middle $(130-148 \mathrm{~mm} \mathrm{Hg}$; mean $=139)$ & $4 \cdot 37(6)$ & $5.95(9)$ & $6 \cdot 12(9)$ \\
\hline Highest $(>148 \mathrm{~mm} \mathrm{Hg}$; mean $=162)$ & $9 \cdot 90(12)$ & $10 \cdot 66(11)$ & $14 \cdot 52(14)$ \\
\hline All & $6 \cdot 48(26)$ & $6.94(29)$ & $7.99(31)$ \\
\hline
\end{tabular}


have accounted for a higher degree of vascular disease in the high renin group.

Another difference between the two studies is that the MRC group did not measure urinary sodium. The association was directly between plasma renin activity and outcome events. They suggest, however, that this is probably not an important issue since most patients in the New York study were classified by virtue of their renin, because most urinary sodium values fell into the 50 to $200 \mathrm{mmol}$ range. Within this range, variation in sodium excretion does not alter renin profile classification. On this latter point, the MRC group may well be correct. More recent findings from a continuation of the New York study, confirming the original findings (now in 3904 subjects contributing 107 cardiovascular disease events), have shown that plasma renin activity, without indexing for sodium excretion, is directly and continuously related to the occurrence of myocardial infarction (Alderman MH, Ooi WL, Cohen H, Madhavan S, Sealey JE, Laragh JH. Am $\mathcal{f}$ Hypertens, in press).

In addition, the method for assaying plasma renin activity differed. The MRC group did not control for cryoactivation. They note, however, that the demographic distribution of subjects, according to plasma renin activity, was similar to that observed in New York and elsewhere. The MRC group also calls attention to the existence of considerably more end point events, $86 v 27$, and particularly fatal ischaemic heart disease, $51 v 9$, than in the New York group.

The major difference, the MRC investigators acknowledge, between the two studies is that while the New York study exclusively involved hypertensive subjects, the British group studiously avoided those with high blood pressure, as well as those who had sustained a previous myocardial infarction. As noted above, subgroup analysis revealed a tendency toward more coronary events among those hypertensive persons who had higher plasma renin activity. They postulate that the sequence of events that might explain such a relationship is that damage to the renal vasculature may blunt the usual inverse relation between blood pressure and plasma renin activity, thus explaining the observed association in hypertensive subjects and its absence in normotensive subjects who are presumably without renovascular damage.

In a letter to The New England fournal of Medicine, the New York investigators suggested a somewhat modified interpretation of the British report. ${ }^{15}$ They contend that in normal subjects, plasma renin activity participates in the feedback control mechanism for maintenance of appropriate blood pressure and flow. Therefore, in normal subjects (both human and animal models), as blood pressure rises plasma renin activity falls. Indeed, according to this model, hypertensive persons ought to suppress plasma renin activity entirely. In fact, any renin activity is physiologically inappropriate among hypertensive persons. Thus, Laragh and his associates would argue that an increased risk of myocardial infarction requires the coexistence of raised plasma renin activity and raised blood pressure. They also note that, in the Meade report, those hypertensive subjects who sustained a myocardial infarction within five years had $50 \%$ greater plasma renin activity than did those without myocardial events. The significance of this finding was not reported.

In reply, Meade and coauthors contend that the subgroup analysis of their data is a less appropriate approach than examination of the entire dataset. ${ }^{16}$ By that more rigorous epidemiological guideline, there was no relation between baseline renin and subsequent coronary artery events.

\section{A synthesis of the British and American views}

Although this author is hardly unbiased, all participants to the debate recounted above agree that the two reports may indeed be compatible. Plasma renin activity, when reflecting its appropriate physiological role in controlling blood pressure in the normotensive individual, is not a measure of cardiovascular risk. On the other hand, in patients with high blood pressure in whom plasma renin should be suppressed, the persistence of a raised level is inappropriate and may generate the kind of pathological vascular effects shown in animal models and clinical trials. Thus, while epidemiological studies are not of themselves capable of establishing causality, the observational data are consistent with the biological rationale that generated the original study.

\section{Clinical trials of renin blocking agents}

Further supportive data linking the reninangiotensin system to coronary artery disease derive from clinical trials with morbidity and mortality end points. These trials compare treatment involving blockade of the reninangiotensin system with some other form of therapy. The completed trials exclusively involve secondary prevention. The most sustained research effort has addressed the issue in patients who have experienced a myocardial infarct. In studies throughout the world, now involving more than 100000 patients, cardioprotection through treatment with converting enzyme inhibition has consistently been achieved. ${ }^{17}$

The major studies are of several types. One group consisted of high risk myocardial infarction survivors, usually with evidence of left ventricular dysfunction. The cardiac risk in such subjects is great, and the benefit from treatment (whether begun early or later) in both the long and the short term has been substantial, generally exceeding $20 \%$. Other studies have involved a broader range of patients, including many at low cardiovascular risk. In these, reduction of subsequent morbidity and mortality has also been achieved, but the absolute benefit has been less. It is felt that effects on vascular remodelling, as so elegantly displayed in studies by Dahlöf, contribute importantly to the favourable effects produced by blocking the renin-angiotensin system. 
Other cardioprotective actions may well also be operative.

Studies in patients with heart failure have also produced favourable cardiac outcomes. The SOLVD trial involved outcome assessment, through a clinical trial, by evaluating the value of adding converting enzyme inhibition to conventional treatment of heart failure. ${ }^{18}$ Patients with chronic heart failure were randomly allocated - in addition to the digitalis and diuretics most were already receiving - to either placebo or enalapril. The study was not designed to address the issue of cardioprotection and the control population did have a slightly higher diastolic pressure, albeit within the normal range, than the enalapril treated group. Nevertheless, during more than three years of follow up, while all cause and particularly heart failure death rates fell, there was, in addition, a non-significant $28 \%$ reduction in myocardial infarction deaths $(53 v 40) .{ }^{18}$ More recently, Lewis et al have reported evidence that converting enzyme inhibition affects favourably the course of renal insufficiency in diabetic subjects. ${ }^{19}$

\section{Summary}

The findings at hand, from animal and human experimentation as well as clinical trials, all point in one direction. There is a strong relation between the plasma renin-angiotensin system and coronary artery disease. Moreover, these findings are consistent with the theoretical understanding of the effects of angiotensin II. What remains to be determined, through studies under way, is the causal nature of the linkage of the renin-angiotensin system and myocardial infarction in a primary prevention trial. This can be done through a prospective randomised clinical trial of hypertensive patients in which blockade of the reninangiotensin system is compared to other equally effective antihypertensive treatments. Such studies are under way. If antirenin therapy proves to add incrementally to the less than satisfactory cardiac prevention achieved by conventional diuretic based antihypertensive therapy, the public health benefit of understanding the link of renin to heart attack will have been realised. ${ }^{20}$
1 Laragh $\mathrm{JH}$, Sealey JE. Renin system understanding for analysis and treatment of hypertensive patients: a means to quantify the vasoconstrictor elements, diagnose curable

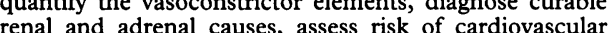
renal and adrenal causes, assess risk of cardiovascular morbidity, and find the best-ft drug regimen. In: Laragh $\mathrm{JH}$ and Brenner BM, eds. Hypertension: pathophysiology, diagnosis, and managem

2 Gavras H, Lever AF, Brown JJ, Macadam RF, Robertson II. Acute renal failure, tubular necrosis, and myocardial JI. Acute renal failure, tubular necrosis, and myocardial
infarction induced in the rabbit by intravenous infarction induced in the rabbi

3 Brunner HR, Laragh JH, Baer L Newton MA, Goodwin FT, Krakoff LR, et al. Essential hypertension: renin and FT, Krakoff LR, et al. Essential hypertension: renin and 286:441-9.

4 Winternitz MC, Mylon E, Waters LL, Katzenstein R. Studies on the relation of the kidney to cardiovascular disease. F Biol Med 1940;12:623-79.

5 Masson GMC, Mikasa A, Yasuda H. Experimental vascular disease elicited by aldosterone and renin. Endocrinology 1962;71:505-12.

6 Giese J. Renin, angiotensin and hypertensive vascular damage: a review. $A m$ f Med 1973;55:315-32.

7 Giacomelli F, Anversa P, Wiener J. Effect of angiotensininduced hypertension on rat coronary arteries and myocardium. Am $\mathcal{F}$ Pathol 1976;84:111-38.

8 Chobanian AV, Haudenschild CC, Nickerson C, Drago R. Antiatherogenic effect of captopril in the Watanabe heritable hyperlipidemic rabbit. Hypertension 1990;15: 327-31.

9 Gavras H, Gavras I. Cardioprotective potential of angiotensin converting enzyme inhibitors. $\mathcal{F}$ Hypertens 1991;9: 385-92.

10 Mettauer B, Rouleau JL, Daly P. The effect of captopril on the coronary circulation and myocardial metabolism of patients with coronary artery disease. Postgrad Med $f$ 1986;62 (suppl 1):54-8.

11 Dahlöf B, Herlitz H, Aurell M, Hansson L. Reversal of cardiovascular structural changes when treating essential hypertension. The importance of the renin-angiotensinaldosterone system. Am f Hypertens 1992;5:900-11.

12 Alderman MH, Madhavan S, Ooi WL, Cohen H, Sealey $\mathrm{JE}$, Laragh JH. Association of the renin-sodium profile with the risk of myocardial infarction in patients with hypertension. N Engl F Med 1991;324:1098-104.

13 Alderman MH, Madhavan S, Cohen H, Sealey JE, Laragh $\mathrm{JH}$. Low urinary sodium is associated with greater risk of myocardial infarction among treated hypertensive men. Hypertension 1995;25:1144-52.

14 Meade TW, Cooper JA, Peart WS. Plasma renin activity and ischemic heart disease. $N$ Engl $\mathcal{f}$ Med 1993;329: 616-9.

15 Alderman $\mathrm{MH}$, Sealey JE, Laragh JH. Plasma renin activity and ischemic heart disease [letter; comment]. $N$ Engl $f$ Med 1994;330:506-7.

16 Meade TW, Cooper JA, Peart WS. Plasma renin activity and ischemic heart disease. $N$ Engl $\mathcal{F}$ Med 1993;329: $616-9$

17 Pfeffer MA. ACE inhibition in acute myocardial infarction [editorial; comment]. N Engl ₹ Med 1995;332:118-20.

18 The SOLVD Investigators. Effect of enalapril on survival in patients with reduced left ventricular ejection fractions and congestive heart failure. $N$ Engl $\Im$ Med 1991;325: 293-302.

19 Lewis EJ, Hunsicker LG, Bain RP, Rohde RD. The Collaborative Study Group. The effect of angiotensinconverting-enzyme inhibition on diabetic nephropathy (Published erratum appears in $N$ Engl f Med 1993;330: 152). N Engl f Med 1993;329:1456-62.

20 Collins R, Peto R, MacMahon S, Hebert P, Fiebach NH, Eberlein KA, et al. Blood pressure, stroke, and coronary heart disease. Part 2. Short-term reductions in blood pressure: overview of randomised drug trials in their epidemiological context. Lancet 1990;335:827-38. 